\title{
AS DIVERSAS FORMAS DE OFERTAR VALOR PARA 0 CLIENTE EM SISTEMAS DE SERVIÇOS
}

THE DIFFERENT FORMS OF PROPOSING VALUE FOR CUSTOMER IN SERVICES SYSTEMS

\section{Leila Scanfone}

scanfone@uol.com.br

Universidade Federal de Minas Gerais (UFMG), Belo Horizonte/MG, BRASIL

\section{Noel Torres Junior}

noel@face.ufmg.br

Universidade Federal de Minas Gerais (UFMG), Belo Horizonte/MG, BRASIL

\section{Marlusa De Sevilha Gosling}

mg.ufmg@gmail.com

Universidade Federal de Minas Gerais (UFMG), Belo Horizonte/MG, BRASIL

\section{Resumo}

A criação, a coprodução e a cocriação são modelos de oferta de valor para o cliente amplamente apresentados na literatura de operações e de marketing de serviços. Contudo, existem lacunas quanto ao entendimento das especificidades de cada modelo e ao modo como as organizações podem aplicá-los. Posto isto, à luz das teorias de criação de valor, o objetivo deste trabalho é elucidar estes três modelos de oferta de valor por meio da apresentação, análise e discussão de três sistemas de serviços de informação sobre trânsito. Para tal, a partir dos dados obtidos em sites, revistas, fóruns e blogs especializados e por meio de observação direta, buscouse identificar como a oferta de valor é implementada em cada serviço estudado. Os resultados apontaram diferenças significativas entre os modelos quanto ao papel do cliente, às formas de interação e às possibilidades de realização de valor pelos os atores envolvidos no processo de serviço.

Palavras-chave: Criação de valor. Cocriação de valor. Coprodução de valor. Serviços.

\begin{abstract}
Creation, co-production and co-creation are models of proposing value to the customer presented extensively in the operations and services marketing literature. However, there are gaps in our understanding of the specifics of each model and how organizations can apply them. Hereupon, in light of approaches of value creation, the aim of this paper is to elucidate these three models of proposing value through the presentation, analysis and discussion of three systems of traffic information services. To this end, from the data from websites, magazines, specialized forums and blogs and through direct observation, we sought to identify how the value offering is implemented in each service studied. The results showed significant differences between the models regarding the role of the client the forms of interaction and possibilities of realization of value by the actors involved in the service process.
\end{abstract}

Keywords: Value creation. Value co-creation. Value co-production. Services. 


\section{Introdução}

No atual ambiente de negócios, há um crescente interesse na compreensão do processo de oferta de valor. Principalmente, quando se considera a mudança pela qual a concepção da criação de valor passa, da troca entre um produtor e um consumidor, para um processo interativo entre empresas, clientes e outras partes interessadas.

Neste contexto, Maull, Geraldi e Johnston (2012) apontam que ao substituir a compreensão do valor como algo criado pela empresa (valor em troca) pelo entendimento de valor como algo decorrente da percepção do cliente (valor em uso), as organizações precisarão rever suas formas de atuação e de posicionamento com e para o cliente.

Deve-se considerar ainda, que as diferenças entre bens e serviços quanto ao modo de criação de valor podem ser significativas (GIANNAKIS, 2011). Neste sentido, Normann e Ramírez (1993) argumentam que enquanto para grande parte das organizações manufatureiras, a adição de valor se dá pelos diversos elos da cadeia produtiva de maneira independente do cliente, por outro lado, para grande parte das organizações de serviços, o valor é construído "para" e "com" o cliente.

Nesta segunda perspectiva, a criação de valor pode ser entendida como cocriação. Nela a efetivação do valor não ocorre por meio de uma cadeia de processos, mas por meio de uma constelação de atores que constroem valor. O principal elemento presente nesta abordagem é a reconfiguração da forma como o relacionamento e os papéis entre os atores existem e são construídos nesta constelação. Neste contexto, a inclusão de novos atores e papeis é facilitada (NORNAMM e RAMÍREZ, 1993). Contudo, o arcabouço teórico sistematizado sobre o tema ainda se encontra em fase de desenvolvimento e consolidação. Entretanto, a cocriação é um construto bem disseminado na literatura de marketing, sendo apontado por alguns autores como um elemento fundamental para o marketing de serviços (GRÖNROOS e VOIMA, 2013).

Contudo, a despeito do maior envolvimento do cliente em vários serviços e tendo o mesmo um papel central para a efetivação dos processos, grande parte dos trabalhos sobre o tema adota uma perspectiva de análise voltada para a organização fornecedora do serviço em detrimento de uma perspectiva voltada para o cliente. Além disto, os estudos que descrevem como as organizações estão implementando o processo de envolvimento dos clientes nas atividades de desenvolvimento de produtos e de criação de valor são poucos (BORGES, 2011) e, em sua maioria, concentram-se na indicação de práticas organizacionais que facilitam estes processos (CHATHOTH et al., 2013).

Diante do exposto e considerando o grande avanço e o acesso às novas tecnologias de informação e comunicação que, além de proporcionarem inúmeras formas de comunicação e interação entre consumidores e empresas e com outros consumidores (HUERTAS et al., 2012), proporcionaram novas formas de atuação do cliente nos processos de criação de valor (THOMKE e HIPPEL, 2002) e coprodução de bens, serviços e experiências (PAYNE; STORBACKA e FROW, 2008; RAMASWAMY, 2011), este trabalho, à luz das teorias de criação de valor, tem por objetivo ilustrar os modelos de criação, coprodução e cocriação de valor. Para tanto, três serviços de informação sobre trânsito ofertados por meio de aplicativos disponibilizados gratuitamente via internet (NavFree, MapLink Trânsito e Waze) são analisados. A análise destes serviços é feita mediante o entendimento, a aplicação e a discussão dos conceitos referentes aos três modelos de oferta de valor apresentados na literatura de operações e marketing de serviços.

\section{Serviços: definições e classificações}

$\mathrm{Na}$ literatura recente, serviços podem ser definidos, pelo menos, a partir de três perspectivas diferentes: conjunto de atividades ou processos, criação de valor para o cliente, e as atividades do provedor (GRÖNROOS, 2008). Contudo, a pesquisa conduzida por Edvardsson, Gustafsson e Roos (2005) com diversos especialistas sobre as definições de serviços, apontou que as mesmas, apesar de diferentes, são pouco abrangentes. Nas definições apresentadas, ora serviços são percebidos como uma categoria de oferta para o mercado, ora como uma perspectiva de criação de valor. Entretanto, os autores argumentam que uma definição geral para serviços pode não ser exequível. A mesma "deve ser determinada em um momento específico, em uma empresa específica, para um serviço específico, a partir de uma perspectiva específica". (EDVARDSSON; GUSTAFSSON e ROOS, 2005, p. 119). Os autores ressaltam ainda a importância de se retratar o serviço a partir da perspectiva de criação conjunta de valor, tendo-se como referência o valor para o cliente. Assim sendo, 
a caracterização de serviços deve ser balizada em sua "natureza interativa, processual, experimental e relacional" (EDVARDSSON; GUSTAFSSON e ROOS, 2005, p. 118).

Do mesmo modo que ocorre com sua definição, as tipologias em serviços também apresentam inúmeras perspectivas e, embora, existam tentativas de criar classificações a partir do contexto de serviços, as mesmas são realizadas a partir de diferentes pontos de vista, resultando em benefícios distintos e dificultando a criação de uma classificação única (SILVESTRO et al., 1992).

Todavia, considerando os serviços que serão apresentados e discutidos neste trabalho, optou-se pela proposta apresentada por Lovelock (1983). O autor considerou duas dimensões, a natureza do ato do serviço (tangível ou intangível) e quem recebe diretamente o serviço (pessoas ou posses). Estas dimensões desdobram-se em quatro categorias: processamento de pessoas (tangível/pessoas), processamento de posses (tangível/posses), processamento de estímulo mental (intangível/ pessoa) e processamento de informações (intangível/ posses) (Quadro 1).

\section{Quadro 1: Quatro categorias de serviços}

\begin{tabular}{|c|c|c|}
\hline \multirow{2}{*}{$\begin{array}{l}\text { Qual a } \\
\text { natureza do } \\
\text { serviço? }\end{array}$} & \multicolumn{2}{|c|}{$\begin{array}{c}\text { Quem ou o que recebe diretamente os } \\
\text { serviços? }\end{array}$} \\
\hline & Pessoas & Posses \\
\hline $\begin{array}{l}\text { Ações } \\
\text { tangíveis }\end{array}$ & $\begin{array}{l}\text { Processamento de } \\
\text { pessoas (serviços } \\
\text { dirigidos ao corpo das } \\
\text { pessoas) } \\
\text { - Transporte de } \\
\text { passageiros } \\
\text { - Hospedagem } \\
\text { - Serviços de saúde }\end{array}$ & $\begin{array}{l}\text { Processamento de } \\
\text { posses (serviços } \\
\text { dirigidos às posses } \\
\text { físicas) } \\
\text { - Transporte de } \\
\text { Cargas } \\
\text { - Reparos e } \\
\text { Manutenção } \\
\text { - Lavanderia } \\
\text { convencional e } \\
\text { a seco. }\end{array}$ \\
\hline $\begin{array}{l}\text { Ações } \\
\text { intangíveis }\end{array}$ & $\begin{array}{l}\text { Processamento de } \\
\text { estímulo mental } \\
\text { (serviços dirigidos à } \\
\text { mente das pessoas) } \\
\text { - } \quad \text { Educação } \\
\text { - } \quad \text { Propaganda/ } \\
\quad \text { Relações públicas } \\
\text { - } \quad \text { Psicoterapia }\end{array}$ & $\begin{array}{l}\text { Processamento } \\
\text { de informações } \\
\text { (serviços dirigidos a } \\
\text { ativos intangíveis) } \\
\text { - } \quad \text { Contabilidade } \\
\text { - } \quad \text { Serviços } \\
\text { bancários } \\
\text { - Assessoria } \\
\quad \text { jurídica }\end{array}$ \\
\hline
\end{tabular}

Fonte: Lovelock (1983, p.12).
Considerando esta classificação, os serviços apresentados e discutidos neste trabalho são classificados como de processamento de informações.

Postoisto, faz-se necessário apresentar as características de cada modelo de oferta de valor, antes de realizar a análise de cada um dos sistemas de informação que são objetos deste estudo.

\section{As teorias de criação de valor}

Prover o cliente com algo que lhe satisfaça ou gere benefícios, ou seja, crie valor a partir da perspectiva do mesmo, é um elemento essencial para a sobrevivência de uma organização (HAKSERVER et al., 2000). Contudo, este é um processo que pode ser implementado de diferentes modos. Na literatura de operações e marketing de serviços, três modelos são bastante discutidos. São eles: a criação de valor, a coprodução de valor e a cocriação de valor.

O modelo de criação de valor, apresentado por Porter em 1985, aponta que algumas atividades essenciais conduzidas pelas organizações envolvidas na cadeia produtiva são responsáveis pela criação de valor. Neste modelo, o valor é produzido pela organização e entregue ao cliente e é entendido como "o montante financeiro que os compradores estão dispostos a pagar por aquilo que uma empresa lhes fornece" (PORTER, 1998, p. 34). O cliente, portanto, é visto como um agente passivo que recebe o valor criado pela organização. Este modelo se encaixa dentro de uma perspectiva denominada Produto-Dominante. Nesta lógica, a empresa é vista como um sistema fechado, formada internamente por processos e participante de um conjunto de organizações em uma configuração semelhante a uma cadeia linear, com fluxo unidirecional que se inicia nas operações à montante e termina nas operações à jusante. Está lógica é útil para um grande número de indústrias, mas revela muitas limitações se utilizada no contexto das organizações de serviços (NORMANN e RAMÍREZ, 1993).

De maneira diferente da lógica Produto-Dominante, a lógica Serviço-Dominante aponta que uma organização não é capaz de criar valor, ela apenas pode ofertar uma proposição de valor, a qual será aceita (ou não) pelo cliente (LUSCH; VARGO e WESSELS, 2008). Neste sentido, Ramírez (1999) argumenta que em situações de serviços, o valor é reinventado e combinado, por 
meio da interação entre organizações, fornecedores, clientes e outros envolvidos nos processos. Portanto, em serviços, a cocriação, balizada na lógica ServiçoDominante, passa a ser o fundamento para o estudo e análise da oferta de valor (LUSCH; VARGO e O'BRIEN, 2007; PRAHALAD e RAMASWAMY, 2004a, b).

Cabe ressaltar que, a lógica Serviço-Dominante enfatiza a interação entre a empresa e o cliente e tem como princípios: o serviço passar a ser visualizado como um processo; o foco recair em recursos dinâmicos; e a criação de valor ocorrer por meio de um processo colaborativo entre diversos agentes. Portanto, os clientes são elementos centrais que participam no processo produtivo. O produto é o um dos meios utilizados para a entrega do valor, não é mais o foco central de sua construção. Neste contexto, o valor é circunstancial, determinado pelo cliente de acordo com o uso feito pelo mesmo (LUSCH; VARGO e WESSELS, 2008). Diante disto, o valor pode ser entendido como "sendo um processo físico, virtual, mental ou de aquisição que é criado pelo consumidor (individualmente e socialmente), durante o uso de recursos existentes nos processos e por seus resultados" (GRÖNROOS e VOIMA, 2013, p. 140).

Em outras palavras,

Quando o valor é percebido como valor em uso para o cliente, o foco não é mais predominantemente num pacote personalizado de produtos ou serviços trocados por um preço. Em vez disso, a criação de valor torna-se um processo contínuo, que enfatiza as experiências, a lógica e a capacidade do cliente para extrair valor além dos produtos e dos outros recursos utilizados (criar valor em uso). (GRÖNROOS e VOIMA, 2013, p, 135).

Todavia, para uma melhor compreensão das mudanças necessárias para o reposicionamento da organização para a lógica Serviço-Dominante, faz-se necessário compreender as diferenças entre a mesma e a lógica Produto-Dominante. Na lógica ProdutoDominante, o cliente tem um papel passivo e a organização não reconhece a questão da reciprocidade e interdependência entre empresa e consumidores. Por outro lado, na lógica Serviço-Dominante, os dois últimos elementos são os fundamentais e o cliente passa a desempenhar um papel ativo no processo de criação de valor (PRAHALAD e RAMASWAMY, 2004a, b; LUSCH; VARGO e O'BRIEN, 2007). Portanto, a criação de valor para o cliente na lógica Serviço-Dominante, enquanto processo, deve ser compreendida como algo "dinâmico, interativo, não linear e muitas vezes, decorrente de processos inconscientes" (PAYNE; STORBACKA e FROW, 2008, p. 86).

Neste contexto, Grönroos (2008) aponta que duas perspectivas devem ser consideradas no processo de cocriação a partir da lógica Serviço-Dominante. A perspectiva do consumidor, na qual por meio da realização do processo pelo cliente, ele cria valor para si mesmo. A perspectiva do fornecedor, na qual ao proporcionar as interações, ele cria valor para si mesmo e para os clientes. Estas duas abordagens possibilitam a ampliação da oferta, a expansão do mercado e propiciam aos fornecedores influenciarem na realização do valor pelo cliente e, portanto, fazerem mais que apenas propor valor. Os modelos de criação de valor de acordo com a realização de valor na lógica de serviço e na lógica de produtos (o modelo de realização de valor e o modelo de facilitação de valor), respectivamente, assim como no contexto do valor em troca (o modelo de valor de troca) são expostos no Quadro 2. 


\section{Quadro 2: Duas perspectivas no processo de cocriação a partir da lógica Serviço-Dominante}

\begin{tabular}{|c|c|c|}
\hline & Fornecedor & Consumidor \\
\hline \multicolumn{3}{|c|}{ Criação de valor em uso de acordo com a lógica de serviços } \\
\hline \multicolumn{3}{|c|}{ Modelo de realização de valor } \\
\hline Papel & $\begin{array}{l}\text { Valor facilitador ao proporcionar aos consumidores } \\
\text { uma base para a criação de valor para si mesmos, na } \\
\text { forma de recursos (bens, serviços, informações ou } \\
\text { outros recursos). } \\
\text { Valor cocriador durante envolvimento direto nas } \\
\text { interações com os clientes no decurso dos processos } \\
\text { geradores de valor para eles mesmos (consumo). }\end{array}$ & $\begin{array}{l}\text { Valor criador (1) durante o processo de geração de valor } \\
\text { (consumo) onde, se necessário, outros recursos disponíveis } \\
\text { para os clientes e habilidades por eles detidas são adicionados e, } \\
\text { (2) Através de interações de suporte para o valor com } \\
\text { fornecedores como prestadores de serviços durante os } \\
\text { processos de geração de valor, onde a realização do valor } \\
\text { ocorre. }\end{array}$ \\
\hline \multicolumn{3}{|c|}{ Criação de valor em uso de acordo com a lógica de produtos } \\
\hline \multicolumn{3}{|c|}{ Modelo de facilitação de valor } \\
\hline Papel & $\begin{array}{l}\text { Valor facilitador ao proporcionar aos consumidores } \\
\text { uma base para a criação de valor, na forma de } \\
\text { recursos (bens, serviços, informações ou outros } \\
\text { recursos). }\end{array}$ & $\begin{array}{l}\text { Criador de valor durante o processo de geração de valor } \\
\text { (consumo), onde outros recursos necessários disponíveis para } \\
\text { os clientes e habilidades por eles detidas são adicionados e onde } \\
\text { o valor de realização ocorre. }\end{array}$ \\
\hline \multicolumn{3}{|c|}{ Criação de valor em troca } \\
\hline \multicolumn{3}{|c|}{ Modelo de valor em troca } \\
\hline Papel & $\begin{array}{l}\text { Criador de valor em troca por meio da produção de } \\
\text { bens e serviços para serem trocados por dinheiro ou } \\
\text { equivalente. }\end{array}$ & $\begin{array}{l}\text { Criador do valor em uso durante os processos de geração de } \\
\text { valor (consumo) onde o valor ocorre e onde o nível do valor } \\
\text { em troca da empresa é determinado. }\end{array}$ \\
\hline
\end{tabular}

Fonte: Grönroos (2008, p. 308).

Considerando ainda as perspectivas do consumidor e do provedor, porém, a partir das esferas nas quais a criação de valor pode ocorrer, Grönroos e Voima (2013) propõem que o valor pode ser criado em três diferentes esferas (do produtor; do cliente; e comum - produtor e cliente), em diferentes momentos e em diferentes sequências e padrões (GRÖNROOS e VOIMA, 2013). Isto pode ser visualizado na Figura 1.

Figura 1: Esferas de criação de valor

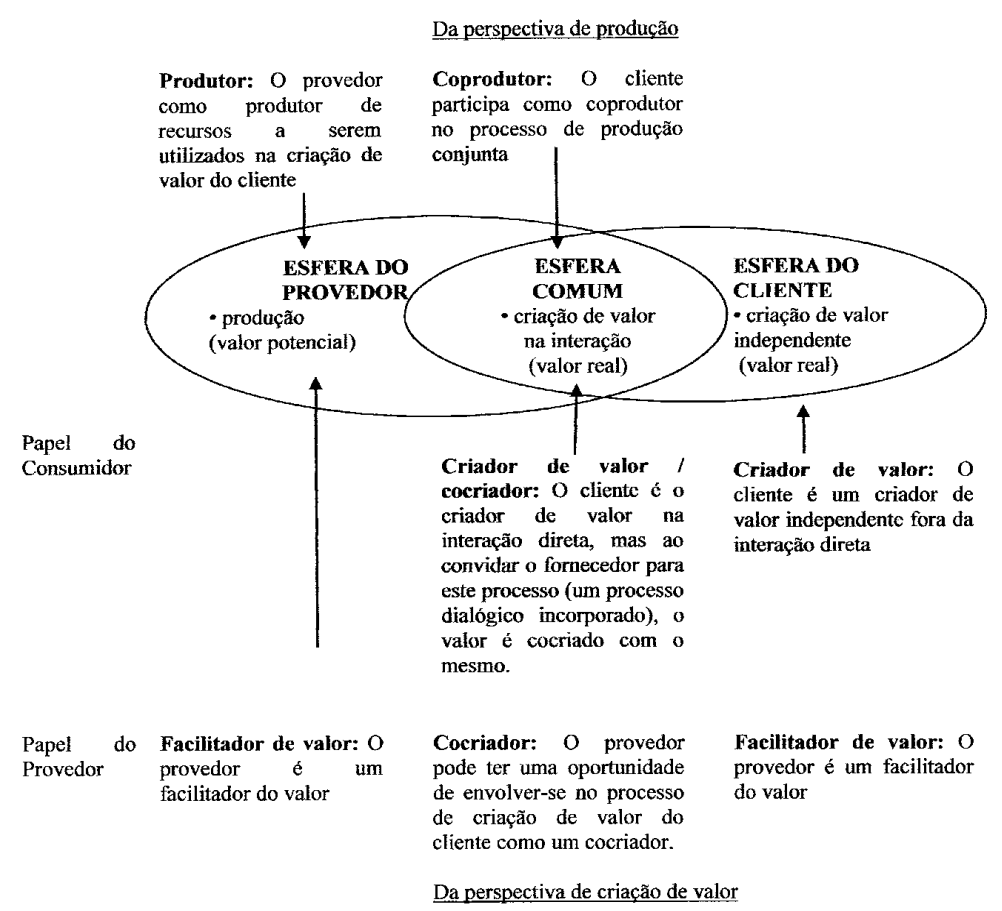

Fonte: Grönroos e Voima (2013, p. 140). 
No entanto, para o valor ser efetivado, é essencial o engajamento e a ocorrência de uma experiência significativa do consumidor no processo de desenho/ realização do serviço (CHATHOTH et al., 2013). Portanto, a promoção de um diálogo efetivo com o consumidor durante estes processos é fundamental (PLÉ e CÁCERES, 2010). A organização deve dispor de certa infraestrutura que possibilite a vivência de uma experiência significativa para e pelo cliente (PRAHALAD e RAMASWAMY, 2004a).

Ainda em relação às experiências, Ballantyne e Varey (2006,p.335) apontam trêsatividades como facilitadoras das mesmas no ambiente de serviço e que influenciam na criação de valor. São elas: relacionamento, interação comunicativa e conhecimento. O relacionamento é decorrente das interações. Principalmente, das "relações que são benéficas para todas as partes e que fornecem o apoio estrutural que é útil para sustentar a promoção das atividades de criação de valor". A interação pode ser informativa, comunicacional ou dialógica. No contexto da criação de valor, o diálogo dá apoio à cocriação de valor. Por fim, a aplicação e o compartilhamento do saber, principalmente o tácito, é fonte de renovação do conhecimento.

Diante disto, as experiências adquiridas pelos atores, decorrentes das interações dos consumidores com empresa, funcionários e outros consumidores, por meio da infraestrutura e recursos disponibilizados pela organização, passam a ser o foco do processo e a interação, o lócus da criação de valor. (PRAHALAD e RAMASWAMY, 2004a).

Neste contexto, Grönroos e Voima (2013, p. 140) apontam que

Interações são situações em que as partes que interagem estão envolvidos nas práticas umas dos outras. O núcleo de interação é um contato físico, virtual ou mental, de modo que o provedor cria oportunidades para se envolver com experiências e práticas dos seus clientes e, assim, influenciar o seu fluxo e os resultados.

Corroborando, Helkkula et al. (2012) citados por Grönroos e Voima (2013, p. 144), apontam que estas interações entre cliente e provedores de serviços nem sempre ocorrem na realidade física, "as interações podem ser apenas a explicitação de expectativas ou assumir a forma de interações indiretas com o serviço, como por meio de comunicação entre pares, recomendações boca a boca, revisões, ou anúncios". Além disto, Tapscott e Williams (2007) sugerem que a interação traz inúmeras oportunidades para os atores que estiverem diretamente conectados às redes de relacionamento sustentadas por ferramentas como a Internet.

Além do exposto até aqui, faz-se necessário apresentar as diferenças entre coprodução e cocriação de valor, uma vez que ambos são processos de criação de valor e que demandam o envolvimento do cliente. Chathoth et al. (2013) sugerem que antes de serem abordagens dicotômicas, coprodução e cocriação são partes de um continum, quando analisadas sob a perspectiva do tipo de envolvimento/diálogo com o cliente versus princípio da criação de valor. A matriz oriunda desta perspectiva apresenta quatro categorias de processos de produção de serviços. São elas: customização, cocriação, coprodução e inovação em serviço, conforme apontado na Figura 2.

Figura 2: Matriz coprodução para cocriação

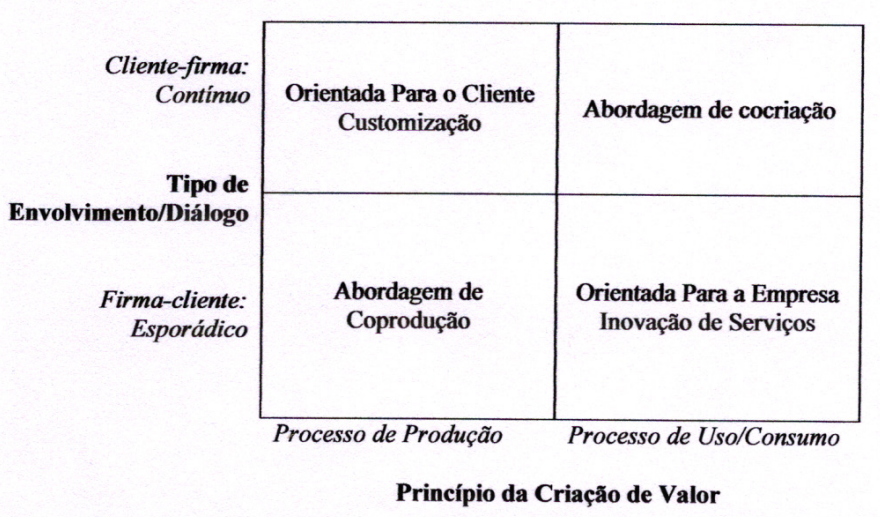

Fonte: Chathoth et al. (2013, p. 15).

Contudo, embora processos não dicotômicos, coprodução e cocriação são elementos que possuem características específicas. O Quadro 3 apresenta as principais diferenças entre estas duas abordagens, a partir dos seguintes elementos: 1) criação de valor: conceito; 2) papel do cliente; 3) participação do cliente: modo como a participação do cliente ocorre; 4) foco; 5) inovação: como a inovação é conduzida; e 6) comunicação: modo como a comunicação entre a empresa e seus clientes ocorre. 
Quadro 3 - Comparando coprodução com cocriação

\begin{tabular}{|c|c|c|}
\hline & Coprodução & Cocriação \\
\hline $\begin{array}{l}\text { (1) Criação de } \\
\text { valor }\end{array}$ & $\begin{array}{l}\text { Obtenção de valor } \\
\text { econômico. } \\
\text { Produtos e } \\
\text { serviços de } \\
\text { qualidade. }\end{array}$ & $\begin{array}{l}\text { Criação de } \\
\text { experiências } \\
\text { personalizadas } \\
\text { exclusivas. }\end{array}$ \\
\hline $\begin{array}{l}\text { (2) Papel do } \\
\text { cliente }\end{array}$ & $\begin{array}{l}\text { Passivo (dependem } \\
\text { do ambiente físico } \\
\text { fornecido). } \\
\text { Percebido como } \\
\text { um recurso. }\end{array}$ & $\begin{array}{l}\text { Ativo (fornecer } \\
\text { dados ao prestador } \\
\text { de serviços antes, } \\
\text { durante e depois do } \\
\text { serviço). } \\
\text { Fornecedor de } \\
\text { informação. } \\
\text { Criador de valor. }\end{array}$ \\
\hline $\begin{array}{l}\text { (3) } \\
\text { Participação } \\
\text { do cliente }\end{array}$ & $\begin{array}{l}\text { Principalmente, no } \\
\text { final da cadeia de } \\
\text { valor. }\end{array}$ & $\begin{array}{l}\text { Interações repetidas } \\
\text { e transações por } \\
\text { meio de múltiplos } \\
\text { canais. } \\
\text { Serve como um } \\
\text { recurso operante. }\end{array}$ \\
\hline $\begin{array}{l}\text { Expectativas } \\
\text { do cliente }\end{array}$ & $\begin{array}{l}\text { Atender às suas } \\
\text { necessidades } \\
\text { com o que está } \\
\text { disponível. }\end{array}$ & $\begin{array}{l}\text { Cocriação de } \\
\text { produtos e serviços } \\
\text { com os clientes. }\end{array}$ \\
\hline Atores chave & $\begin{array}{l}\text { Gerentes e } \\
\text { funcionários. }\end{array}$ & $\begin{array}{l}\text { Cliente, gerentes e } \\
\text { funcionários. }\end{array}$ \\
\hline (4) Foco & $\begin{array}{l}\text { Produção é } \\
\text { centrada na } \\
\text { empresa. }\end{array}$ & $\begin{array}{l}\text { Cliente e centrada } \\
\text { na experiência. } \\
\text { Engajamento dos } \\
\text { clientes. } \\
\text { Alto nível de } \\
\text { processamento de } \\
\text { informações. }\end{array}$ \\
\hline (5) Inovação & $\begin{array}{l}\text { Liderada pela } \\
\text { empresa. }\end{array}$ & $\begin{array}{l}\text { Coinovação e } \\
\text { codesenho com } \\
\text { clientes. } \\
\text { Aprender com os } \\
\text { clientes (líderes } \\
\text { de opinião e } \\
\text { formadores de } \\
\text { opinião) e com o } \\
\text { processo. }\end{array}$ \\
\hline $\begin{array}{l}\text { (6) } \\
\text { Comunicação }\end{array}$ & $\begin{array}{l}\text { Ouvir os clientes. } \\
\text { Menos } \\
\text { transparente. }\end{array}$ & $\begin{array}{l}\text { Diálogo permanente } \\
\text { com os clientes. } \\
\text { Comunicação aberta } \\
\text { e transparente. }\end{array}$ \\
\hline
\end{tabular}

Fonte: Chathoth et al. (2013, p. 15).
A partir do apresentado no Quadro 3 e utilizando as palavras de Ramaswamy (2011, p.195) cocriação pode ser compreendida como "o processo pelo qual o valor mútuo é expandido em conjunto [...]" e o que a direciona é "envolver as pessoas para criar experiências valiosas em conjunto e simultaneamente reforçando a economia de rede". Importante ressaltar, também, que o processo de cocriação depende da quantidade de informações, conhecimentos, habilidades e outros recursos operantes que os clientes podem acessar e usar (NORMANN 2001; VARGO e LUSCH, 2004; PAYNE; STORBACKA e FROW, 2008).

Complementando, Prahalad e Ramaswamy (2004a, p. 23-31) apontam que o diálogo, o acesso, a avaliação de risco e a transparência devem ser entendidos como elementos primordiais para o processo e a realização da cocriação. O diálogo refere-se "à interatividade, envolvimento profundo e propensão a agir de ambas as partes (cliente e fornecedor)". O acesso refere-se à experiência desejada pelo consumidor e não necessariamente à posse do produto e começa pelas informações e ferramentas disponibilizadas pelo provedor ao consumidor. A avaliação do risco relaciona-se à divulgação da "probabilidade de dano ao consumidor", ou seja, do risco pessoal ou social associado ao produto ou serviços. Contudo, do mesmo modo que o consumidor consegue avaliar melhor o risco devido ao maior acesso às informações, este passa a assumir maior responsabilidade pela minimização dos mesmos. A transparência envolve uma maior simetria de informações que é a base para a promoção da confiança entre os envolvidos.

Por fim, de acordo com Normann e Ramírez (1993), o processo de criação de valor sob a ótica da cocriação traz três implicações estratégicas para as organizações: 1) mobilização dos consumidores para criarem valor para eles próprios; 2) reconfiguração dos relacionamentos e sistemas de negócios da organização; e 3) a chave para a criação de valor é a produção conjunta, fazendo com que a vantagem competitiva esteja relacionada à capacidade de conceber e implementar um sistema de criação de valor. Portanto, a cocriação exige repensar o negócio e a organização. Em relação ao negócio, reconhecem-se as diferenças nos papéis dos atores envolvidos e as formas dos mesmos se relacionarem. Já, as organizações necessitam rever suas estruturas, pensando em propiciar o surgimento de novas ofertas e na facilitação das inter-relações dos atores. (RAMÍREZ, 1999). 


\section{Método da pesquisa}

Para atingir o objetivo de elucidar, à luz das teorias de criação de valor, os modelos de oferta de valor, o presente estudo possui cunho qualitativo-descritivo e foi desenvolvido por meio do estudo de múltiplos casos.

$\mathrm{Na}$ pesquisa qualitativa, busca-se a construção da realidade por meio de palavras e procedimentos específicos de pesquisa, sendo que este processo

pode ser representado como uma trajetória que parte da teoria em relação ao texto, e outra do texto de volta para a teoria. A intersecção dessas duas trajetórias é a coleta de dados verbais ou visuais e a interpretação destes em um plano de pesquisa específico (FLICK, 2009, p. 27).

Por sua vez, o estudo descritivo de natureza qualitativa, de acordo com Minayo et al. (2001), possibilita a exposição das características de determinada população, a análise dos fatos e fenômenos de determinada realidade e a busca pela descoberta ou verificação de ligações entre determinadas variáveis.

A opção pelo estudo de caso, deu-se em função de ser um método de pesquisa em ciências sociais que possibilita compreender em profundidade o fenômeno em estudo (YIN, 2005) e ao estudar múltiplos casos, é possível comparar e observar como as diversas variáveis se comportam de acordo com cada objeto analisado (FLICK, 2009).

Posto isto e considerando a revisão bibliográfica sobre as teorias de criação de valor realizada, a escolha dos casos ocorreu primeiramente por meio da busca de um serviço de informações para dispositivos de telefonia móvel que possibilitasse: 01) a participação ativa e em tempo real do cliente, diretamente no serviço, enquanto este estivesse sendo prestado para ele e para os demais clientes e 02) a troca de informações entre fornecedor, clientes e demais interessados. Estes elementos foram escolhidos, uma vez que representam respectivamente o papel do cliente como ativo (cliente como fornecedor de informação/criador de valor) e conhecimento compartilhado e aplicado. Estes elementos são apontados na teoria de cocriação de valor como características fundamentais da mesma.
Diante do expressivo número de aplicativos existentes, optou-se por analisar os aplicativos listados entre os 30 melhores aplicativos de 2012 pela EXAME.com (GREGO, 2012). Dos 30 aplicativos apresentados, somente o Waze atendeu aos dois critérios. Escolhido o Ware, buscou-se por mais dois aplicativos que fornecessem o mesmo tipo de serviço, porém, que apresentassem características das demais teorias de criação de valor. Neste sentido, buscou-se um aplicativo que não possibilitasse a participação dos usuários como fornecedor de informação durante o processo do serviço (papel passivo - cliente como receptor do serviço) e o conhecimento não fosse compartilhado e outro que permitisse a participação de usuários no fornecimento de informações, porém, antes do processo de serviço (papel passivo - cliente percebido como recurso) e o conhecimento fosse pouco compartilhado.

Determinados os aplicativos, a coleta dos dados sobre o modo de funcionamento dos mesmos e suas especificidades foi realizada por meio de análise documental. Neste sentido, utilizou-se como fonte de dados as páginas (web sites) especializadas e em notícias/artigos sobre tecnologia.

Para complementar a coleta de dados, optou-se pela utilização de observação direta. Neste aspecto, durante o período de junho a agosto de 2013 os autores deste trabalho utilizaram os aplicativos em seus deslocamentos diários e acompanharam as publicações de usuários em fóruns de discussão, blogs e páginas nas redes sociais dos próprios aplicativos.

Por fim, para a apresentação e discussão dos achados, optou-se pela elaboração de um quadro que permitisse relacionar as principais características dos modelos de criação de valor a cada um dos aplicativos estudados.

\section{Apresentação dos aplicativos}

\section{0 aplicativo Navfree}

Lançado em 2010, pela Navmii Holding plc, empresa sediada em Londres, fundada em 2009, o NavFree é um aplicativo de navegação gratuito que utiliza como base cartográfica os dados do OpenStreetMap e é atualizado mensalmente (NAVMII, 2013). Atualmente, o aplicativo possui 15 milhões de usuários (APPLE, 2013b).

1 Uma espécie de Wikipédia de mapas. 
A interface do aplicativo é semelhante à de grande parte dos programas de GPS, armazena mapas offline e permite compartilhar a localização do usuário por meio do Facebook, e Twitter, e-mail e SMS. As buscas podem ser realizadas por endereços, pontos de interesse (POI) e por meio do Google ou do Microsoft Bing.

As funcionalidades do aplicativo são (GOOGLE, 2013b): cálculos rápidos de itinerário, recálculos automáticos de itinerário, demonstração de itinerário no mapa, verificação de todas as etapas do itinerário a partir da lista de endereços, pesquisa de pontos de interesse, pesquisa de endereços e modo de navegação pedestre.

Além do aplicativo gratuito, a empresa oferece um aplicativo pago, o Navmii, que oferece o mesmo serviço, porém, baseado em outra fonte de dados (NAVMII, 2013).

\section{O aplicativo MapLink Trânsito}

O MapLink Trânsito é um aplicativo gratuito de mapas, rotas e informações sobre trânsito, lançado em 2012 e distribuído pela empresa brasileira MapLink, fundada em 2000. Atualmente, possui menos de $500 \mathrm{mil}$ usuários. O aplicativo trabalha sobre as plataformas iOS, Android e Windows (GOOGLE, 2013a).

A base cartográfica de dados é o Google Maps e as informações sobre o trânsito são oriundas de clientes que fornecem posições de veículos circulando no Brasil inteiro anonimamente, as mesmas são processadas e calculadas em uma plataforma inteligente de trânsito para compilação de dados como latitude, longitude, velocidade e azimute (medida de direção horizontal, definida em graus). A partir disto, processam-se as velocidades médias de deslocamento desses veículos dentro da base cartográfica (MAPLINK, 2013).

As funcionalidades do aplicativo são (GOOGLE, 2013a; SANTI, 2012; TECHTUDO, 2011):

- Situação em tempo real do trânsito das cidades de: Salvador, BA/ Vitória, ES/ Goiânia, GO/ Belo Horizonte, MG/ Cuiabá, MT/ Recife, PE/ Curitiba, $\mathrm{PR} /$ Rio de Janeiro, RJ/ Barueri, SP/ Campinas, $\mathrm{SP} /$ Diadema, SP/Guarulhos, SP/ Osasco, SP/ Santo André, SP/ São Bernardo do Campo, SP/ São Caetano, SP/ São Paulo, SP;

- Notícias e informações sobre incidentes em tempo real;
- Cálculos de rotas.

- Descrição da área de Rodízio;

- Situação do trânsito geral no mapa e detalhado por via;

- Imagem das câmeras de rodovias e cidades;

- Inserir em favoritos: cidades, rodovias e câmeras;

- Compartilhar as informações do trânsito no Facebook e Twitter.

$\mathrm{Na}$ tela principal do aplicativo há cinco botões no rodapé. Em "Mapa", o aplicativo localiza onde você está por meio do GPS ativado. Em "Cidades", você escolhe o local que deseja e depois a avenida ou rua para verificar a situação do trânsito: lento, fluxo intenso, fluindo ou livre. Já, na opção "Rodovias", basta escolher a cidade ou a visualização das principais BRs do Brasil. Para ter acesso às câmeras, clicar no ícone "Câmeras". Se quiser ler notícias e informações, clicar no último botão representado por três pontinhos (TECHTUDO, 2011).

Além do aplicativo gratuito, a empresa oferece soluções corporativas no que tange a serviços de trânsito (Ex.: Webservices e APIs de mapeamento e roteirização).

\section{O aplicativo Waze}

O Waze é um aplicativo gratuito de mapeamento, trânsito e navegação (APPLE, 2013a), lançado em 2008, em Israel e, em 2009, globalmente. Em junho de 2013 foi vendido para o Google por cerca de 1 bilhão de dólares, após receber ofertas da Apple e do Facebook (TANJI, 2013). O aplicativo possui mais de 70 milhões de usuários no mundo (APPLE, 2013a), sendo que no Brasil, são 2,1 milhões de usuários (PAPP, 2013). Trabalha sobre as plataformas iOS, Android, Symbian e Windows Mobile.

O serviço prestado por meio do aplicativo é a indicação da rota de trânsito mais rápida, a partir das informações compartilhadas pelos próprios usuários e em tempo real. Aliando as funcionalidades de um GPS às potencialidades de uma rede social, o aplicativo além de fornecer a rota mais rápida até o destino indicado pelo usuário, possibilita que os usuários mantenham-se informados e informem, em tempo real, as condições do trânsito. 
De acordo com Nishi (2012, p. 18),

O objetivo do Waze é permitir aos usuários traçarem suas rotas como se fosse um GPS automotivo normal, porém, caso essa rota que o usuário está seguindo obtiver informações de ocorrências reportadas por outros usuários, ele recalcula automaticamente outra rota.

Em relação ao trânsito, os usuários podem informar, por meio de textos ou fotos: dados sobre acidentes (acidentes), locais de congestionamento (trânsito), problemas que denotem perigo para o motorista (perigo), pontos de blitz (polícia) e outros eventos que podem alterar o fluxo da via. Ao trafegar com o aplicativo ativado, ela fornece informações sobre, por exemplo, a velocidade da via na qual o usuário está se locomovendo. O próprio mapa pode ser atualizado pelos usuários.

Outras informações disponíveis no aplicativo e que são atualizadas pelos próprios usuários são: localização dos postos de gasolina e os preços dos combustíveis praticados pelos mesmos, restaurantes, posto policial, entre outros pontos de interesse que estejam no perímetro próximo do usuário.

Além disto, o aplicativo permite a integração com Facebook, Foursquare e a criação de grupos para envio de mensagens (texto ou voz) para outros usuários. O mapa de deslocamento também pode ser compartilhado por SMS ou e-mail com quem não possui o aplicativo.

De acordo com Ayres (2011), o que diferencia e o Waz̧e de outros aplicativos de informações sobre trânsito é que os mapas são desenhados/atualizados por meio de informações dos próprios usuários. Por exemplo, quando um usuário transita por uma rota não traçada, o sistema permite que estas vias sejam gravadas e, posteriormente, encaminhadas à comunidade de usuários para correção e validação, que são imediatamente aprovadas e incorporadas ao sistema.

\section{Discussão dos serviços à luz das teorias de criação de valor}

Conforme apontado no referencial teórico, no contexto atual de serviços, o cliente passa a ter um papel ativo na prestação de serviços. Isto pode ser observado na dinâmica dos três aplicativos quanto às informações de navegação. Em todos os serviços, para que a rota entre dois destinos seja traçada, os usuários devem informar o ponto de origem e o ponto de destino. Contudo, no caso do MapLink trânsito e no $W$ aře, os clientes também participam na produção do serviço ao fornecerem informações sobre trânsito. Diante disto, o processo, as possibilidades de interação e os resultados dos serviços são bastante diferentes.

No NavFree o usuário fornece os dados do ponto de origem e do ponto de destino e o aplicativo aponta a rota mais rápida, a partir dos dados do mapa. Durante o percurso, caso o usuário se depare com algum incidente, deverá solicitar que uma nova rota seja traçada. No MapLink Trânsito o usuário fornece os dados do ponto de origem e do ponto de destino e o aplicativo aponta três alternativas de itinerário, a partir dos dados do mapa e dos dados referentes ao trânsito fornecidos por alguns clientes. Ao longo do percurso, o usuário poderá buscar novas informações sobre incidentes ou áreas de trânsito intenso e recalcular sua rota. No Waze o usuário fornece os dados do ponto de origem e do ponto de destino e o aplicativo aponta a rota mais rápida, a partir de um mapa atualizado pelos próprios usuários e de uma base de dados atualizada em tempo real, também, pelos próprios usuários do aplicativo. Durante o percurso, conforme os incidentes vão sendo informados pelos próprios usuários, o aplicativo automaticamente encontra e aponta a rota alternativa mais rápida e/ou recalcula o tempo que será necessário para chegar ao destino.

Diante do exposto, o que se pode observar é que nos três casos, o valor criado é o "valor em uso", ou seja, os serviços só criam valor enquanto estão sendo prestados. Tanto as rotas quanto as informações sobre tráfego (no caso do MapLink Trânsito e do Waře), por exemplo, só farão diferença para os usuários e servirão de base para o provedor dos serviços sugerir uma nova rota, no momento em que são fornecidas. Isto reforça a colocação de Grönroos e Voima (2013) sobre a criação de valor ser um processo contínuo e não se restringir a simples troca de um pacote fechado por uma determinada quantia de dinheiro.

Todavia, apesar do valor em uso ser comum aos três aplicativos, pode-se observar que no NavFree a criação de valor ocorre em conformidade com a perspectiva da lógica Produto-Dominante, ou seja, no modelo 
de facilitação de valor (Ver Quadro 2). Em outras palavras, o aplicativo não permite a interação entre o usuário e a organização ou entre os próprios usuários. Contudo, o provedor fornece o recurso para a criação de valor. Neste sentido, o provedor é o facilitador dos serviços ao fornecer o aplicativo e o usuário o criador de valor durante a utilização da informação gerada por ele.

Por sua vez, no MapLink Trânsito e no Waže a criação do valor se dá a partir do modelo de criação de valor em uso de acordo com a lógica ServiçosDominante, ou seja, no modelo de realização de valor (Ver QUADRO 2). Todavia, enquanto no MapLink Trânsito observa-se a coprodução de valor, no Waz̧e o processo alcança a cocriação. O MapLink Trânsito , por exemplo, permite que alguns usuários participem como fornecedores das informações relativas ao trânsito. Ao observar as características apontadas por Chathoth et al. (2013), como de coprodução, podese depreender que no caso do MapLink Trânsito, o cliente é passivo, pois é percebido como um recurso, a participação do cliente acorre ao final da cadeia de valor, embora alguns possam fornecer informações durante o uso do serviço, a produção é centrada na empresa e a comunicação consiste em ouvir os clientes e esta pode ser vista como pouco transparente. No Waze, por sua vez, pode-se observar a criação de experiências personalizadas exclusivas, papel ativo do cliente, pois, o mesmo fornece a informação antes, durante e depois do serviço, a participação do cliente se dá por meio de interações repetidas, o mesmo é um recurso operante, o processo é centrado na experiência, há engajamento dos clientes, alto nível de processamento de informação, diálogo permanente com os clientes e a comunicação é aberta e transparente. Portanto, todos os elementos apontados por Chathoth et al., (2013) podem ser observados no Waze.

Além disto, adotando a perspectiva de Ramaswamy (2011 p. 195) de que o que direciona a cocriação é "envolver as pessoas para criar experiências valiosas em conjunto, reforçando simultaneamente a economia de rede" e que cocriação "é o processo pelo qual o valor mútuo é expandido em conjunto [...]", pode-se observar que o aplicativo Waze é o único que viabiliza estes elementos. Ao permitir que usuários reportem e recebam diversos tipos de informações em tempo real, o aplicativo proporciona a criação de experiência conjunta e a economia de rede. Por exemplo, ao utilizar as informações dos próprios usuários para fazer uma nova oferta de valor para o cliente, como traçar uma nova e melhor rota, o provedor do serviço auxilia na expansão do valor mútuo em conjunto.

Considerando que de acordo com Prahalad e Ramaswamy (2004a, b), as experiências personalizadas decorrentes das interações dos consumidores com empresa, funcionários e outros consumidores, por meio da infraestrutura disponibilizada pela organização, são o foco do processo e a interação o lócus da criação de valor, o Waze, ao possibilitar a comunicação/diálogo entre pares e com a empresa e fazendo desta comunicação/diálogo o meio de construção do próprio serviço, propicia a construção das experiências personalizadas e a construção conjunta do valor. Por exemplo, ao possibilitar a comunicação / interação entre pares, podem-se formar grupos de pessoas que fazem o mesmo percurso todos os dias, possibilitando a oferta de caronas ou rodízio de carros entre os integrantes do grupo.

Além da comunicação/diálogo, os demais elementos destacados na teoria, como meios para a efetivação do processo de cocriação como: relacionamento, conhecimento (BALLANTYNE e VAREY, 2006), acesso, a avaliação do risco e a transparência (PRAHALAD e RAMASWAMY, 2004 a, b), estão presentes no serviço prestado por meio do Waze. O relacionamento se constrói, mesmo que virtualmente, diante das diversas interações. O Compartilhamento do conhecimento se mostra por meio da atualização das informações sobre trânsito, dos mapas e das informações sobre os pontos de interesse. O acesso ocorre com a utilização do serviço, ou seja, ao experimentá-lo. Em relação à avaliação do risco, o processo é compartilhado, basta observar a necessidade de verificação, pelo gestor de área, da veracidade das informações sobre novas rotas. Por fim, a transparência pode ser observada ao verificar que as mesmas informações que são disponibilizadas para os usuários servem para o provedor fazer a nova proposta da melhor rota.

Em relação aos papéis tanto do provedor quanto do consumidor, conforme modelo proposto por Grönroos e Voima (2013), observa-se que no Wazu há todos os modos citados na perspectiva da criação de valor, conforme Quadro 4. 
Quadro 4 : Papéis dos usuários e do provedor do Waze nas esferas de criação de valor.

\begin{tabular}{|c|c|c|c|}
\hline & \multicolumn{3}{|c|}{ Esferas da Criação de Valor } \\
\hline & Esfera do Provedor & Esfera Comum & Esfera do Cliente \\
\hline \multirow{2}{*}{$\begin{array}{l}\text { Papel do } \\
\text { Consumidor }\end{array}$} & & Criador de valor / cocriador. & Criador de Valor \\
\hline & & $\begin{array}{l}\text { O usuário ao reportar } \\
\text { informações cria valor para si e } \\
\text { cocria valor com o provedor. }\end{array}$ & $\begin{array}{l}\text { O usuário ao receber o serviço } \\
\text { cria o valor para si mesmo. }\end{array}$ \\
\hline $\begin{array}{l}\text { Papel do } \\
\text { Provedor }\end{array}$ & $\begin{array}{l}\text { Facilitador de valor } \\
\text { O aplicativo é o meio pelo } \\
\text { qual o provedor facilita a } \\
\text { criação de valor. }\end{array}$ & $\begin{array}{l}\text { Cocriador } \\
\text { O provedor ao utilizar as } \\
\text { informações recebidas para gerar } \\
\text { novas rotas para os usuários } \\
\text { cocria valor com os usuários. }\end{array}$ & $\begin{array}{l}\text { Facilitador do Valor } \\
\text { Ao possibilitar a interação entre } \\
\text { pares facilita a criação de valor } \\
\text { pelos usuários. }\end{array}$ \\
\hline
\end{tabular}

Fonte: elaborado pelos autores a partir Grönroos e Voima (2013, p. 140).

Diante do exposto, pode-se depreender que o processo de criação de valor ofertado pelo Waže, se enquadra no que Normann e Ramírez (1993) denominaram “Constelação de Valor”. Uma vez que há a reconfiguração da forma da relação e dos papéis entre os atores que formam a constelação, que novas formas de valor são adicionadas por novos participantes, os quais têm sua entrada facilitada e que há a mobilização dos clientes para criarem valores para si próprios.

Por fim, o Quadro 5 sintetiza as principais ideias apresentadas.

Quadro 5: Síntese dos principais aspectos dos aplicativos à luz das teorias da criação de valor

\begin{tabular}{|c|c|c|c|}
\hline & NavFree & MapLink trânsito & Waze \\
\hline $\begin{array}{l}\text { Oferta de valor } \\
\text { predominante }\end{array}$ & Criação de valor & Coprodução de valor & Cocriação de valor \\
\hline $\begin{array}{l}\text { Modelo de Criação de } \\
\text { valor em uso } \\
\text { (Grönroos, 2008) }\end{array}$ & $\begin{array}{l}\text { Modelo de facilitação } \\
\text { de valor (Fornecedor - } \\
\text { propicia aos usuários o } \\
\text { recurso para a criação de } \\
\text { valor. Usuários - Cria valor } \\
\text { ao utilizar o recurso). }\end{array}$ & $\begin{array}{l}\text { Modelo de realização } \\
\text { de valor (Fornecedor - } \\
\text { propicia aos usuários o } \\
\text { recurso para a criação } \\
\text { de valor para si mesmos. } \\
\text { Usuário - Cria valor ao } \\
\text { utilizar o recurso). }\end{array}$ & $\begin{array}{l}\text { Modelo de realização de valor } \\
\text { (Fornecedor - cocria valor } \\
\text { ao gerar novas informações } \\
\text { durante o uso do recurso pelo } \\
\text { consumidor. Usuário - Cria valor } \\
\text { para si e fornece informações que } \\
\text { geram valor para o fornecedor e } \\
\text { demais usuários). }\end{array}$ \\
\hline $\begin{array}{l}\text { Papel do Cliente } \\
\text { (Chathoth et al., 2013) }\end{array}$ & $\begin{array}{l}\text { Passivo (receptor do } \\
\text { serviço). }\end{array}$ & $\begin{array}{l}\text { Passivo (Percebido como } \\
\text { um recurso). Alguns } \\
\text { usuários fornecem } \\
\text { informações. }\end{array}$ & $\begin{array}{l}\text { Ativo (Fornecedor de informação } \\
\text { / Criador de valor). }\end{array}$ \\
\hline $\begin{array}{l}\text { Participação do Cliente } \\
\text { (Chathoth et al., 2013) }\end{array}$ & $\begin{array}{l}\text { No final da cadeia de valor } \\
\text { ao utilizar as informações } \\
\text { do aplicativo. } \\
\\
\text { Atender as suas } \\
\text { necessidades com o que } \\
\text { está disponível. }\end{array}$ & $\begin{array}{l}\text { Há possibilidade de } \\
\text { participação de alguns } \\
\text { usuários durante o uso } \\
\text { do serviço, ao fornecer } \\
\text { informações. Ao final } \\
\text { da cadeia ao utilizar } \\
\text { as informações do } \\
\text { aplicativo. } \\
\text { Atender as suas } \\
\text { necessidades com o que } \\
\text { está disponível. }\end{array}$ & $\begin{array}{l}\text { Interações repetidas ao longo do } \\
\text { uso do aplicativo. O usuário é um } \\
\text { recurso operante. }\end{array}$ \\
\hline
\end{tabular}




\begin{tabular}{|c|c|c|c|}
\hline $\begin{array}{l}\text { Foco } \\
\text { (Chathoth et al., 2013) }\end{array}$ & $\begin{array}{l}\text { Produção é centrada na } \\
\text { empresa. }\end{array}$ & $\begin{array}{l}\text { Produção é centrada na } \\
\text { empresa. }\end{array}$ & $\begin{array}{l}\text { Produção é centrada na } \\
\text { experiência. }\end{array}$ \\
\hline $\begin{array}{l}\text { Interação comunicativa } \\
\text { (Ballantyne e Varey, 2006; } \\
\text { Chathoth et al., } 2013 \text { e } \\
\text { Prahalad e Ramaswamy, } \\
2004 \text { a) }\end{array}$ & $\begin{array}{l}\text { Informativa. Inexistente. } \\
\text { (Não há comunicação entre } \\
\text { fornecedor e usuário). }\end{array}$ & $\begin{array}{l}\text { Comunicacional. } \\
\text { Ouvir os clientes. } \\
\text { Fechada. } \\
\text { (Alguns usuários } \\
\text { fornecem informações } \\
\text { para o fornecedor). }\end{array}$ & $\begin{array}{l}\text { Dialógica. } \\
\text { Dialogar com os clientes. } \\
\text { Aberta. (Fornecedor e usuários } \\
\text { e usuários com usuários trocam } \\
\text { informações com frequência). }\end{array}$ \\
\hline $\begin{array}{l}\text { Relacionamento } \\
\text { (Interação com os } \\
\text { clientes) } \\
\text { (Ballantyne e Varey, 2006) } \\
\end{array}$ & $\begin{array}{l}\text { Inexistente. (Não há } \\
\text { interação entre fornecedor } \\
\text { e usuário). }\end{array}$ & $\begin{array}{l}\text { Esporádicas. (Há } \\
\text { pouca interação entre } \\
\text { fornecedor e usuário). }\end{array}$ & $\begin{array}{l}\text { Frequentes. (Fornecedor e } \\
\text { usuários e usuários com usuários } \\
\text { interagem com frequência). }\end{array}$ \\
\hline $\begin{array}{l}\text { Transparência } \\
\text { (Prahalad e Ramaswamy, } \\
2004 \text { a) }\end{array}$ & $\begin{array}{l}\text { Não transparente } \\
\text { (Informação de posse } \\
\text { somente do fornecedor). }\end{array}$ & $\begin{array}{l}\text { Pouco transparente } \\
\text { (Alguns usuários } \\
\text { compartilham } \\
\text { informações com o } \\
\text { fornecedor). } \\
\end{array}$ & $\begin{array}{l}\text { Transparente } \\
\text { (Fornecedor e usuários } \\
\text { compartilham abertamente as } \\
\text { informações). }\end{array}$ \\
\hline $\begin{array}{l}\text { Conhecimento } \\
\text { (Ballantyne e Varey, 2006) }\end{array}$ & Não Compartilhado & $\begin{array}{l}\text { Pouco Compartilhado } \\
\text { (Fornecedor e alguns } \\
\text { usuários compartilham } \\
\text { conhecimento). }\end{array}$ & $\begin{array}{l}\text { Compartilhado e aplicado } \\
\text { (Fornecedor e usuários } \\
\text { compartilham e aplicam o } \\
\text { conhecimento. Ex.: edição dos } \\
\text { mapas). }\end{array}$ \\
\hline
\end{tabular}

Fonte: elaborado pelos autores a partir de Ballantyne e Varey (2006), Chathoth et al. (2013), Grönroos (2008) e Prahalad e Ramaswamy (2004a).

\section{Considerações Finais}

Diante das mudanças na concepção e no processo de criação de valor (GRÖNROOS, 2008; GRÖNROOS e VOIMA, 2013); LUSCH; VARGO e O’BRIEN, 2007; LUSCH; VARGO e WESSELS, 2008; NORMANN E RAMIREZ, 1993; PRAHALAD e RAMASWAMY, 2004a, b) e consequente necessidade de readequação, por parte das organizações, quanto à forma de atuar e de posicionar-se com e para o cliente (MAULL, GERALDI E JOHNSTON, 2012; RAMIREZ, 1999), no cenário organizacional atual, compreender o processo de oferta de valor faz-se essencial.

Neste sentido, este trabalho teve como objetivo elucidar, à luz das teorias de criação de valor, três modelos de oferta de valor apresentados na literatura, por meio da apresentação e análise dos processos de três sistemas de serviços de informação sobre trânsito.

O NavFree é o aplicativo de uma empresa sediada em Londres, lançado em 2010 e com 15 milhões de usuários. É um serviço de informações de trânsito voltado para a navegação, baseado em no OpenStreetMap, que oferece aos usuários traçar a rota mais rápida entre dois pontos (NAVMII, 2013). De acordo com as teorias apresentadas, apesar de ser um serviço, sua lógica de criação de valor é baseada na lógica Produto-Dominante. Isto pode ser observado pelo fato de o usuário ser, apenas, o receptor do serviço; o processo de produção do serviço ser centrado no provedor; não haver interação comunicativa entre usuários e fornecedor; e o modelo de criação de valor em uso, ser o de facilitação de valor.

O MapLink Trânsito é um aplicativo de uma empresa brasileira, lançado em 2012 (GOOGLE, 2013 a). É um serviço de navegação e trânsito, prestado por meio de informações oriundas de alguns usuários e compiladas pelo próprio provedor do serviço (MAPLINK, 2013). A lógica de criação de valor observada neste serviço foi a de coprodução de valor, uma vez que o usuário, embora forneça algumas informações, exerce um papel passivo no serviço, e o processamento do serviço é centrado no provedor do serviço. Além disto, apesar do modelo de criação de valor em uso, ser o de realização de valor, as interações entre fornecedor e usuário são esporádicas e restringem-se a ouvir o usuário. 
O Waze é um aplicativo de uma empresa israelense, lançado em 2008, com 70 milhões de usuários (APPLE, 2013a) e vendido para Google em 2013, por cerca de 1 bilhão de dólares (TANJI, 2013). É um serviço de navegação, mapeamento e trânsito, que tem como input para seu processo, informações fornecidas em tempo real pelos usuários que estão trafegando na região. À luz das teorias sobre criação de valor, pode-se observar que o modelo de serviço proporciona a efetivação do modelo de cocriação de valor ao tornar os usuários participantes ativos no processo, permitir interação entre e com os usuários, utilizar e compartilhar o conhecimento dos usuários, criar experiências personalizadas, compartilhar os riscos, possibilitar uma maior simetria ao acesso à informação, entre outros.

Como pode ser depreendido, os achados do estudo apontaram que há diferenças significativas entre os serviços estudados, no que se refere ao papel atribuído ao cliente e a forma de interação entre os diversos atores envolvidos no processo de serviço e consequentemente nas formas de realização do valor para e pelos envolvidos. O que corrobora o exposto nas teorias sobre criação de valor sobre as especificidades de cada modelo.

Contudo, como limitações do estudo, destacam-se a não possibilidade de generalização dos resultados encontrados, devido ao número de casos estudados e o fato dos conceitos inicias terem sido desenvolvidos a partir de pesquisa exploratória na literatura, o que determinou os dados que poderiam ser coletados e delineou a pesquisa. Contudo, como o objetivo do estudo era a melhor compreensão dos modelos de oferta de valor, entende-se que o objetivo foi alcançado.

Por fim, visando a continuidade da discussão e considerando a relevância do tema na área de operações e de marketing de serviços principalmente, sugere-se que futuras pesquisas busquem abordar serviços pagos e que trabalhem no mesmo modelo de oferta de valor. Além disto, sugere-se que se busque identificar a estrutura da rede de serviços necessária para a oferta de cada modelo de valor.

\section{Referências}

APPLE. Waze GPS social e trânsito. 2013a. Disponível em: < https://itunes.apple.com/br/app/ Waze-social-gps-traffic/id323229106? mt=8\&ign$\mathrm{mpt}=\mathrm{uo} \% 3 \mathrm{D} 2>$. Acesso em: 23 ago. 2013.

APPLE. NavFree GPS Brasil + Street view. 2013b. Disponível em: < https://itunes.apple.com/br/app/ navfree-gps-brazil-+-street/id434220438?mt $=8 \quad>$. Acesso em 23 dez. 2013.

AYRES, A. Conheça o Waze, um software de GPS social para iPads e iPhones. MacMagazine. Publicado em 10 jan. 2011. Disponível em: < http://macmagazine. com.br/2011/01/10/conheca-o-Waze-um-softwarede-gps-social-para-ipads-e-iphonesipods-touch/ > Acesso em: 06 ago. 2013.

BALLANTYNE, D.; VAREY, R. J. Creating value-inuse through marketing interaction: the exchange logic of relating, communicating and knowing. Marketing Theory, v. 6, n. 3, p. 335-348, 2006.

BORGES, M. Explorando o uso de plataformas digitais de mídia social por empresas para cocriação com consumidores. 2011. Tese (Doutorado). Programa de Pós-graduação em Administração, Universidade Federal do Rio Grande do Sul, Porto Alegre, 2011. Disponível em: < http://hdl.handle. net/10183/30135 >. Acesso em: 02 ago. 2013.

CHATHOTH, P.; ALTINAY, L.; HARRINGTON, R. J.; OKUMUS, F.; CHAN, E. S. Co-production versus co-creation: a process based continuum in the hotel service context. International Journal of Hospitality Management, v. 32, p. 11-20, 2013.

EDVARDSSON, B.; GUSTAFSSON, A.; ROOS, I. Service portraits in service research: a critical review. International Journal of Service Industry Management, v. 16, n. 1, p. 107-121, 2005.

FLICK, U. Introdução à pesquisa qualitativa. $3 \mathrm{ed}$. Porto Alegre: Artmed, 2009.

GIANNAKIS, M. Conceptualizing and managing service supply chains. The Service Industries Journal, v. 31, n. 11, p. 1809-1823, 2011.

GOOGLE PLAY. MapLink Trânsito. 2013a Disponível em: < https://play.google.com/store/ apps $/$ details $? \mathrm{id}=$ com.lbslocal.transito\&hl $=$ pt_BR $>$. Acesso em: 29 set. 2013. 
GOOGLE PLAY. NavFree: GPS Grátis. 2013b.

Disponível em: < https://play.google.com/store/ apps/details?id=com.navfree.android.OSM. ALL\&hl=pt_BR >>. Acesso em: 06 out. 2013.

GREGO, M. Os 30 melhores apps de 2012 para iPhone, iPad e Android [Online]. EXAME.com, 2012. Disponível em: <http://exame.abril.com.br/ tecnologia/noticias/os-30-melhores-apps-de-2012para-iphone-ipad-e-android $>$. Acesso em: 21 jun. 2013.

GRÖNROOS, C., Service logic revisited: who creates value? And who co-creates? European Business Review, v. 20, n. 4, p. 298-314, 2008.

GRÖNROOS C.; VOIMA, P. Critical service logic: making sense of value creation and $\mathrm{CO}^{-}$ creation. Journal of the Academy of Marketing Science, v. 41, n. 2, p. 133-150, 2013.

HAKSEVER, C.; RENDER, B.; RUSSEL, R. S.; MURDICK, R. G. Service Management and Operations. 2. ed. New Jersey: Prentice Hall, 2000.

HUERTAS, M. K. Z.; VARELA, C. A.;STREHLAU, S. Cocriação na internet: uma análise das perspectivas da empresa e do consumidor. Revista de Administração e Inovação, v. 9, n. 3, p. 257-272, 2012.

LOVELOCK, C. H. Classifying Services to Gain Strategic Marketing Insights, Journal of Marketing, v. 47 , p. 9-20, 1983.

LUSCH, R.F.; VARGO, S.L., O’BRIEN, M. Competing through service: insights from service-dominant logic. Journal of Retailing, n. 83, v. 1, p. 5-18, 2007.

LUSCH, R. F.; VARGO, S. L.; WESSELS, G. Toward a conceptual foundation for service science: contributions from service-dominant logic. IBM System Journal, v. 47, n. 1, p. 5-13, 2008.

MAPLINK. Central de ajuda MapLink. 2013. Disponível em: < http://www.maplink.com.br/ forms/wrong_info_google >. Acesso em: 29 set. 2013.

MAULL, R.; GERALDI, J.; JOHNSTON, R. Service supply chains: a customer perspective. Journal of Supply Chain Management, v. 48, n. 4, p. 72-86, 2012.

MINAYO, M. C. S. Pesquisa social: teoria, método e criatividade. 19. ed. Petrópolis: Vozes, 2001.

NAVMII. Company. Disponível em: < http:// / www. navmii.com/Company >. Acesso em: 06 out. 2013.

NISHI, M. K. Um sistema baseado em inteligência coletiva para visualização de problemas em vias públicas. 2012. 41 f. Trabalho de Conclusão de Curso (Graduação) - Universidade Tecnológica Federal do Paraná, Campo Mourão, 2012. Disponível em: < http://repositorio.roca.utfpr.edu.br/jspui/ handle/1/709 >. Acesso em: 06 ago. 2013.

NORMANN, R. Reframing business: when the map changes the landscape. Chichester: Wiley, 2001.

NORMANN, R.; RAMÍREZ, R. From value chain to value constellation: designing interactive strategy. Harvard Business Review, v. 71, n. 4, p. 65-77, jul./ aug. 1993.

PAPP, A, C. Waze foi eleito aplicativo do ano pela Apple em 2012. R7 Notícias. 2013. Disponível em: < http://noticias.r7.com/tecnologia-e-ciencia/ noticias/Waze-foi-eleito-aplicativo-do-ano-pelaapple-em-2012-20130612.html >. Acesso em: 04 ago. 2013.

PAYNE, A.F., STORBACKA, K., FROW, P. Managing the co-creation of value. Journal of the Academy of Marketing Science, v. 36, n. 1, p. 83-96, 2008.

PLÉ, L., CÁCERES, R.C., Not always co-creation: introducing interactional codestruction of value in service-dominant logic. The Journal of Services Marketing, v. 24, n. 6, p. 430-437, 2010.

PORTER, M. Como as forças competitivas moldam a estratégia. In: MONTEGOMERY, C. A., PORTER, M. A busca da vantagem competitiva. Rio de Janeiro: Campus, 1998.

PRAHALAD, C.K., RAMASWAMY, V. The Future of Competition: co-creating unique value with customers. Boston: Harvard Business School Press, 2004a.

PRAHALAD, C.K., RAMASWAMY, V. Co-creation experiences: the next practice in value creation. Journal of Interactive Marketing, v.18, n. 3, 2004b.

RAMASWAMY, V. It's about human experiences... and beyond, to co-creation. Industrial Marketing Management, v. 40, n. 2, p. 195-196, 2011. 
RAMÍREZ, R. Value co-production: intellectual origins and implications for practice and research. Strategic Management Journal, v. 20, n. 1, p. 49-65, 1999.

SANTI, C. E. G. Análise da aceitação de Sistemas Avançados de Informação ao Condutor-ATIS em cidades brasileiras de porte médio. Dissertação (Mestrado). 2012. Programa de Pós-Graduação em engenharia Civil. Universidade Federal de Santa Catarina,Florianópolis, 2012.Disponívelem: < https:/ / repositorio.ufsc.br/handle/123456789/91545 >. Acesso em: 29 set. 2013.

SILVESTRO, R.; FITZGERALDI, L.; JOHNSTOM, R.; VOSS, C. Towards a Classification of Service Process. International Journal of Service Industry Management, v. 3, n. 3, p. 62-75, 1992.

TANJI, t. Google vence disputa com Facebook e compra o WAZE. INFO Online. 11. Jun. 2013. Disponível em: < http://info.abril.com.br/noticias/ mercado/google-vence-disputa-com-facebook-ecompra-waze-11062013-24.shl >. Acesso em: 15 nov. 2013.

TAPSCOTT, D.; WILLIAMS, A. D. Wikinomics: como a colaboração em massa pode mudar o seu negócio. Rio de Janeiro: Nova Fronteira, 2007.

TECHTUDO. MapLink Trânsito. 2011. Disponível em: < http://www.techtudo.com.br/tudo-sobre/s/ maplink-transito.html >. Acesso em: 29 set. 2013.

THOMKE, S.; HIPPEL, E. V. Customers as innovators: a new way to create value. Harvard Business Review, v. 80, n. 4, p. 74-81, 2002.

VARGO, S. L.; LUSCH, R. F. Evolving to a new dominant logic for marketing. Journal of Marketing, v. 68 , p. 1-17, 2004.

YIN, R. K. Estudo de Caso: planejamento e métodos. 3 ed. Porto Alegre: Bookman, 2005. 